\title{
Structure Equation Model of Perceived Benefits for using Facebook of Thai Teenager
}

\author{
Chanyanan Somthawin pongsai ${ }^{1 *}$, Abdul Jalil Khan ${ }^{2}$, Sairish Sairien ${ }^{3}$, Aphinan Busabok ${ }^{4}$ and \\ Tassanai Wankong ${ }^{5}$
}

${ }^{1}$ Faculty of Business Administration Pathum Thani University, Thailand

${ }^{2}$ Department of Physiotherapy, DHQ Teaching Hospital, KDA Kohat, Pakistan

${ }^{3}$ Doctor of Physiotherapy, University of Lahore Sihala Campus, Pakistan

${ }^{4}$ Doctor of General Business Management, Western University, Thailand

${ }^{5}$ Doctor of General Business Management, The Researchers Association of Thailand, Thailand

*Corresponding author: Chanyanan Somthawin pongsai, Department of Physiotherapy, DHQ Teaching Hospital, KDA Kohat, Pakistan

\section{ARTICLE INFO}

Received: May 13, 2020

Published: 慧 June 02, 2020

Citation: Chanyanan Somthawin p, Abdul Jalil K, Sairish S, Aphinan B, Tassanai W. Structure Equation Model of Perceived Benefits for using Facebook of Thai Teenager. Biomed J Sci \& Tech Res 28(1)-2020. BJSTR. MS.ID.004592.

Keywords: Structure Equation Model; Perceived Benefits; Facebook

\section{Summary}

Background: Past education often studies on issues relating to building and maintaining relationships Self-presentation and fun as for issues related to the use of media to support self-worth and utilization to find oneself there is still little education. This study is therefore interested in studying the need to create clarity in the said phenomenon in the context of Thai society.

Main Objective: To study the causal relationship of factors affecting the perceived usefulness of Facebook usage of Thai teenagers

Methods: Design of study was simple random sampling technique was use collect the data 600 undergraduate students from private universities in the central region of Thailand Who have used Facebook for 2 years were collected by question aires and analyze the elements of perceived benefit by structural equation model (SEM).

Results: The outcomes revealed that the confirmatory factor analysis showed that the perceived benefits model showed that Consistent with the empirical data by considering $=2.70, \mathrm{df}=2, \mathrm{p}=0.259,=1.32, \mathrm{GFI}=1.00, \mathrm{NFI}=1.00, \mathrm{CFI}=1.00, \mathrm{RMR}=0.007$, SRMR $=0.011$, RMSEA $=0.024,=0.805$ and $=0.455$.

Conclusion: This study concluded that perceived benefits are consistent with empirical data based on $=2.70, \mathrm{df}=2, \mathrm{p}=0.259,=1.32, \mathrm{GFI}=1.00, \mathrm{NFI}=1.00, \mathrm{CFI}=1.00$, $\mathrm{RMR}=0.007, \mathrm{SRMR}=0.011$, RMSEA $=0.024,=0.805$ and $=0.455$ show that the design model is harmonious with empirical data. Most high-resolution $(=0.805)$ measurement models can explain the variance of Variables in the benefit evaluation components $(=0.455)$.

\section{Introduction}

Facebook has become an enormous resource that affects the lives of ordinary people. Nowadays, humans can connect and create relationships with Facebook. Which is the nature of interaction through text, images, and sound through the use of technology without limiting space and time? Facebook developed from the concept Social network which emphasizes the existence of the relationship between social relationships between people, extending throughout the society consists of network members on the interaction of exchange [1]. Currently, Facebook millions of users contribute and use social data. Some users are heavily involved in the exchange of information by updating status, posting photos that reflect ideas and the feeling [2]. The study of Mc Kenna et al. [3-5]. The impulse that causes Facebook usage is the motivation to use media and the benefits of using media to reflect the value of compensation [6-8], the evaluation of the benefit factors that influence Facebook usage. A related psychological impulse consists of supporting the self-worth in use. Use to explore yourself in 
Facebook usage. Self-improvement for using Facebook Keeping relationships with others from use. And satisfaction from the fun of using Facebook from presenting my own story Experience to create social acceptance through Facebook and enjoyment and relationship healing [9-13].

Also, the benefits of the relationship Facebook friends are the creation and maintenance of social capital, the assessment, and the connection of social capital bonds. By surveying the dimensions of social capital from the ability of people to communicate with members that have previously lived so maintenance of social capital will affect the measures of the well-being which will have a positive effect on self-esteem and life satisfaction [14-16]. There is also another group of studies that found it useful and users can present their stories $[9,11,17-20]$ in which social presence is the level of human interaction and appearances to other people in a virtual environment, explained by the theory of social presence (Social presence Theory). Identification is the awareness of partnership from social interaction, with the social impact primarily caused by the level of social presence from communication through the media that has the characteristics of interacting back and forth has meaning, the feelings of the communication partners is a medium that makes people come to know each other and have thoughts about others, whose increased appearance leading to people's perception is the level of interaction and the result of interpersonal relationships [21].

Appearing in a virtual environment Is important because it means both direct and indirect contact of humans in online social networks [22], when people engage in virtual social networking websites able to communicate in a way that is similar to face-to-face communication assessing the benefits of self-disclosure in online social networks is the benefit of awareness. About exchanging from using online social networks is a special form exchange that brings about the benefits that are driven by raising awareness of one's own needs by self-desire, self-presentation and entertainment from creating interpersonal relationships to enhance social performance for users $[9,14,23,24]$. Benefits in maintaining relationships. Leading to closeness and intimacy that underscores toughness for online communities [25] Ying-Wei Shih et al., 2015; [18] Ying-Wei Shih et al. 2014.

Also, the advantage of the relationship with friends in online social networks are also creating and the maintenance of social capital is an assessment of the connection between social capital obligations maintaining social capital and raising awareness of one's own needs to determine behavior by self-seeking needs, entertainment, social optimization [14,23]. Besides, the influence of Facebook activities affecting satisfaction in the lives of teenagers becomes part of everyday life for teenagers in society. The issues relating to the use of media to support self-worth. And the use of self-discovery to play a role in the development of identity and create happiness in the lives of today's teens. From the maintenance of social capital, from the creation and maintenance of interpersonal relationships this will have a positive effect on Self-esteem and satisfaction in life and the happiness of teenage life [26]. Past education often studies on issues relating to building and maintaining relationships Self-presentation and fun as for issues related to the use of media to support self-worth and utilization to find oneself there is still little education. This study is therefore interested in studying the need to create clarity in the said phenomenon in the context of Thai society.

\section{Objectives}

To study the causal relationship of factors affecting the perceived usefulness of Facebook usage of Thai teenagers

\section{Research Approach}

The population is 143,997 undergraduate private universities in the central region of Thailand from a total of 42 universities. The sample consisted of 600 undergraduate students from private universities in the central region of Thailand, 100 from 6 universities, namely Kasem-Bundit University. Siam University of the Thai Chamber of Commerce Pathum Thani University Bangkok Thonburi University and Rajapruek University. Each University has come up with a lottery selection. In each university, the researcher will select samples from 2 faculties which are Faculty of Business Administration. And communication arts, 50 faculties per group using cluster random sampling, with classrooms as a sampling unit, calculating sample sizes by using the formula to find the sample size in the case that the dependent variable is quantitative data And know the size of the population Which has the formula for calculation as follows [27].

\section{Expected Benefits}

This knowledge can be developed to measure tools and indexes with high standards in behavioral science. For use in research and development work on the use of online social networks for teens to have the skills to learn to use online social networks under the context of a multicultural society happily. According to the 12th National Economic and Social Development Plan by the strategic framework Balance and develop the public management system on media literacy.

\section{Research Design}

The analysis of the evaluation of past research benefits is a measure of motivation in using media. Utilization and satisfaction with using online social networks. There is research that studies the impulse described by Uses and gratifications: Using online communities to build and maintain relationships. Considered as an incentive to utilize both interpersonal communication keeping track of news and entertainment, motivation to use Facebook is linked to in the real world and the human experience the main objective of the paradigm is to explain why people choose more specific media. Alternative media explained Psychological needs 
that motivate people to use media by assuming that users have goals that are directed at their work [28]. Therefore, the motivation behind Facebook usage is born. From reason to motivation to use media and the benefits of using media to reflect the values of social rewards and achieve goals $[7,8,29]$.

\section{Research Framework}

From the review of relevant researches, the researcher found that Benefit assessment studies often study issues relating to building and maintaining relationships Self-presentation and fun as for issues related to the use of media to support self-worth and utilization to find oneself there is still little education. The issues relating to the use of media to support self-worth. And utilization to find oneself has a role to develop identity and create happiness in the lives of teenagers. To create clarity in the phenomenon Selfdisclosure in online social networks in the context of Thai society the researcher then brought the issues As mentioned for the further study in the assessment measures, the benefits of self-disclosure online social networks have been developed into components. Or apparent variables to measure the evaluation of benefits from self-disclosure in online social networks covering Motivation measurement and satisfaction in using media, divided into 5 characteristics as follows

a. Support for self-value means value derived from success from predetermined objectives which is a study about the attitude of using Facebook. To meet their own needs using Facebook to learn how to behave correctly in various situations to receive news and information to make a decision brainstorm new idea to solve various problems

b. Finding ourselves means understanding yourself through social interaction. It is self-study through other people. To have better understanding in their thoughts and attitudes $[9,30]$.

c. Maintaining interpersonal connections is a study about using Facebook to ease in maintaining relationships and make new friends including off Develop close friendships [31].

d. Value from entertainment is fun. And satisfied with the use of online social networks is a study about using Facebook to relax for entertainment and to cure loneliness

e. Self-presentation is the level of personal interaction and presence with others in a virtual environment $[9,31]$ (Figure 1).

\section{C.M.k. Cheung et al (2011), Jim Yeong Bak, Chin Yewlin, Alice} On (2014)

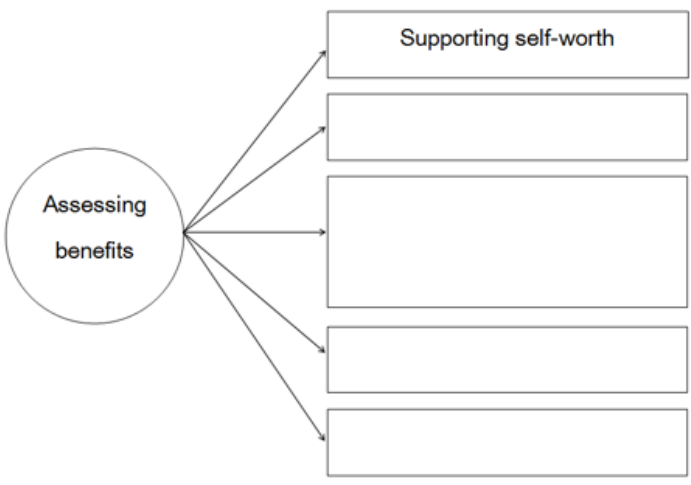

Figure 1: Research conceptual framework.

\section{Findings}

\section{Data Analysis}

Analyze basic statistics about social influence in online social networks of undergraduate students in private universities in the central region of Thailand Using Mean Deviation (SD) in each item and individual variables, skewness, and keratosis and analyze the elements of perceived benefit by structural equation model (SEM).

\section{Research Results}

From Table 1, which shows the Pearson's Product Moment Correlation Coefficient ( $r$ ) and the statistics used to check the suitability of the data, it is found that the observable variables in the 10 benefit evaluation components have a correlation coefficient between 0.358 and 0.661 , the most correlated pair is the selfsupport variable (EB1) and self-searching variable (EB2) with $r$ equal to 0.661 , the pair with The least correlation is the selfsearch variable (EB2) and the relationship maintenance variable (EB3) with r equal to 0.353. Bartlett's Test of Sphericity is 987.744 $(p<.01)$ indicating that the correlation matrix between the variables differs significantly from the identity matrix. And the Kaiser index Mayer-Allkin (Kaiser-Meyer-Olkin measure of sampling adequacy - KMO) equals 0.790, indicating that the observed variables in the perceived usefulness components are sufficiently correlated to the confirmation of the confirmed composition. 
Table 1: Shows the Pearson product moment correlation coefficient of observable variables in the perceived usefulness components.

\begin{tabular}{|c|c|c|c|c|}
\hline Variable & EB1 & EB2 & EB3 & EB4 \\
\hline EB1 & 1.00 & & & \\
\hline EB2 & $0.661^{* *}$ & 1.00 & 1.00 & \\
\hline EB3 & $0.403^{* *}$ & $0.353^{* *}$ & $0.510^{* *}$ & 1.00 \\
\hline EB4 & $0.480^{* *}$ & $0.383^{* *}$ & $0.473^{* *}$ & $0.456^{* *}$ \\
\hline EB5 & $0.502^{* *}$ & $0.426^{* *}$ & 1.00 \\
\hline
\end{tabular}

Note: Cost Bartlett's Test of Sphericity=987.744, $\mathrm{df}=10, \mathrm{p}<.01$ and value $\mathrm{KMO}=0.790$.

Table 2 the results of the confirmatory factor analysis showed that the perceived benefits model showed that Consistent with the empirical data By considering $=2.70, \mathrm{df}=2, \mathrm{p}=0.259$, $=1.32, \mathrm{GFI}=1.00, \mathrm{NFI}=1.00, \mathrm{CFI}=1.00, \mathrm{RMR}=0.007, \mathrm{SRMR}=0.011$, RMSEA $=0.024,=0.805$ and $=0.455$. (Figure 2 ) The measurement model is consistent with the empirical data. The measurement model has the precision of variables in the useful evaluation components. Was at a high level $(=0.805)$ and most of the components could explain the variance of the variables in the useful evaluation components $(=0.455)$. Table 3 considering the importance of standard components, each variable can be observed in the model of cognitive composition, found that every element's weight is positive. And having statistical significance at the level of .01 with sizes from 0.54 to 0.75 , which can be ranked in the order of importance from the highest, which is the entertainment value (EB4) $(=0.75)$, followed by the self-presentation (EB5).) $(=0.75)$ relationship maintenance components (EB3) $(=0.66)$, self-support components (EB1) $(=0.66)$, and self-searching elements (EB2) $(=0.54)$ according to order.

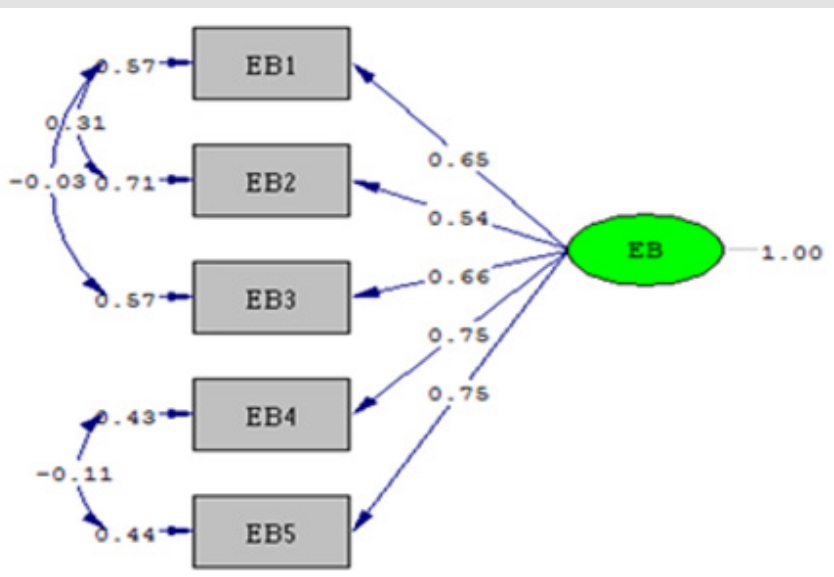

Chi-square=2.70, $d f=2, p-v a l u e=0.25957$, RMSEA $=0.024$

Figure 2: Results of validation of the measurement model, components, and perceived benefits in 5 aspects.

Table 2: Shows the Pearson product moment correlation coefficient of observable variables in the perceived usefulness components.

\begin{tabular}{|c|c|c|c|c|c|}
\hline \multirow{2}{*}{ Variable } & \multicolumn{2}{|c|}{ Weight element } & \multirow{2}{*}{$\mathbf{t}$} & \multirow{2}{*}{$\mathbf{R}^{2}$} & \multirow{2}{*}{$\begin{array}{l}\text { coefficient } \\
\text { Score component }\end{array}$} \\
\hline & b & $\beta$ & & & \\
\hline EB1 & 0.58 & 0.65 & $13.95^{* *}$ & 0.43 & 0.19 \\
\hline EB2 & 0.49 & 0.54 & $12.18^{* *}$ & 0.29 & 0.06 \\
\hline EB3 & 0.51 & 0.66 & $14.32^{* *}$ & 0.43 & 0.25 \\
\hline EB4 & 0.68 & 0.75 & $15.05^{* *}$ & 0.57 & 0.42 \\
\hline EB5 & 0.65 & 0.75 & $14.95^{* *}$ & 0.56 & 0.43 \\
\hline
\end{tabular}

${ }^{* *} \mathrm{p}<.01$

Table 3: Validity of variables in perceived benefit components.

\begin{tabular}{|c|c|c|}
\hline Measurement model & $\rho_{c}$ & $\rho_{v}$ \\
\hline Benefit Assessment Components & 0.805 & 0.455 \\
\hline
\end{tabular}




\section{Conclusion}

The study found that Assessing benefits demonstrate the important role of evaluating the benefits due to the use of Facebook. Its main objective is to create and maintain relationships. According to the theory of utilization and satisfaction from the concept of Katz et al. [28] which describes the expectation of using media to meet the needs of both psychological and social needs. It also plays an important role in establishing teen identity [32] and is a stimulant for self-esteem. The quality of life of teenagers in the present society. It is considered a new way of creating a happy society for teenagers. With many scholars interested in studying such issues this finding underscores the importance of evaluating benefits. Consistent with many research results [2,33-38]. The findings clarify the relationship between perceived benefits. The expansion of online social networks resulting in both opportunities and the risk to the way of life, attitude and belief of people in society as well as interpersonal relations learning process and consumption behavior of people in the country change quickly that Thai society tends to be a very multicultural society.

\section{References}

1. Waner (2010) Global environmental change and migration: governance challenges. Global Environmental Change 20(3): 402-413.

2. Helena, Lee Zach WY, Cheung Christy MK, Chan Tommy KH, Wong Randy YM (2016) A Literature Analysis About Social Information Contribution And Consumption on Social Networking Sites. Research Papers.

3. Mc Kenna KYA, Bargh JA (2000) Plan 9 from cyberspace: the implications of the Internet for personality and social psychology. Personal. Soc. Psychol. Bull 4(1): 57-75.

4. Mazer JP, Murphy RE, Simonds CJ (2007) I'll See You On Facebook: The Effects of Computer- Mediated Teacher Self-Disclosure on Student Motivation, Affective Learning, and Classroom Climate. Communication Education 56(1): 1-17

5. Wang Y, Li C, Lin H, Shih Y (2014) The measurement and dimensionality of e-learning blog satisfaction: Two-stage development and validation, Internet Research 24(5): 546-565.

6. Do he lee, Im Taylor, Cathrine (2008) The Influence of Consumer SelfDisclosure on Web Sites on Advertising Response Journal of Interactive Advertising 9(1): 37-48.

7. Rosenfield LB, Kendrick WL (1984) Choosing to be open: An empirical investigation of subjective reasons for self-disclosing. Western Journal of Speech Communication 48(4): 326-343.

8. Waters, Ackerman (2011) Exploring Privacy Management on Facebook: Motivations and Perceived Consequences of Voluntary Disclosure. Journal of Computer-Mediated Communication 17(1): 101-115.

9. CMK Cheung, Pui Y, MKO Lee (2011) Online social networks: Why do students use facebook? Computers in Human Behavior 27(4): 13371343.

10. Gunn Sara Enli, Nancy Thumim (2012) Socializing and SelfRepresentation online: Exploring Facebook. Observatorio (OBS*) Journal 6(12): 87-105.

11. Utpal M Dholakiaa, Richard P Bagozzia, Lisa Klein Pearo (2004) A socia influence model of consumer participation in network- and smallgroup-based virtual communities. Intern. J. of Research in Marketing 21(3): 241-263.

12. Kuan-Yu Lin, Hsi-Peng Lu (2011) Intention to Continue Using Facebook Fan Pages from the Perspective of Social Capital Theory. Cyberpsychology, Behavior, and Social Networking 14(10): 565-570.
13. Thomas, Chesney (2006) An Acceptance Model for Useful and Fun Information Systems. An Interdisciplinary Journal on Humans in ICT Environments 2(2): 225-235.

14. Nicole B Ellison, Charles Steinfield, Cliff Lampe (2007) The Benefits of Facebook "Friends:" Social Capital and College Students' Use of Online Social Network Sites. Journal of Computer-Mediated Communication 12(4): 1143-1168.

15. Krisaporn Pornprasitwiset (2014) Social capital communication via Facebook and quality of life in the real world Doctoral dissertation, Dhurakij Pundit University.

16. Jin Yeong Bak, Chin-Yew Lin, Alice Oh (2014) Self-disclosure topic model for classifying and analyzing Twitter conversations. Proceedings of the 2014 Conference on Empirical Methods in Natural Language Processing (EMNLP) pp. 1986-1996.

17. Thomas Buckel, Frédéric Thiesse (2014) A comparison of RFID-based shelf replenishment policies in retail stores under suboptimal read rates. International Journal of Production Economics 159: 126-136.

18. Claus Peter H Ernst, Jella Pfeiffer, Franz Rothlauf (2013) The Influence of Perceived Belonging on Social Network Site Adoption. Proceedings of the Nineteenth Americas Conference on Information Systems, Chicago, Illinois, August p.15-17.

19. Kuan-Yu Lin, Hsi-Peng Lu (2011) Why people use social networking sites: An empirical study integrating network externalities and motivation theory. Computers in Human Behavior 27(3): 1152-1161.

20. Hanna Krasnova, Sarah S, Ksenia K, Thomas H (2010) Online Social Networks: Why We Disclose. Journal of Information Technology (JIT) 25(2):109-125

21. Short Williams, Christie (1976) Social presence.

22. Gefen Straub (2004) Validation Guidelines for IS Positivist Research Communications of the Association for Information Systems 3(1): 380427.

23. Cheung Lee, J Chee, H Sung, B Chi, Thomas K, et al. (2009) Pattern of Thyroid Autoimmunity in Chinese Patients With Pernicious Anemia. The American Journal of the Medical Sciences 337(6): 432-437.

24. Cliff Lampe, Nicole B, Charles W (2007) The Benefits of Facebook Friends: Social Capital and College Students' Use of Online Social Network Sites. Journal of Computer-Mediated Communication 12(4): 1143-1168.

25. Rosen, Sherman (2006) Hedonic Information Systems: Acceptance of Social Networking. Proceedings of the Twelfth Americas Conference on Information Systems, Acapulco, Mexico.

26. Wenninger Helena, Krasnova Hanna, Buxmann Peter (2014) Activity Matters: Investigating the Influence of Facebook on Life Satisfaction of Teenage Users. Twenty Second European Conference on Information Systems, Tel Aviv 2014

27. Cooper DR, Schindler PS (2001) Business Research Methods. McGrawHill Higher Education, (12 ${ }^{\text {th }}$ Edn.), London, UK.

28. Katz E (1959) Mass Communications Research and the Study of Popular Culture: An Editorial Note on a Possible Future for This Journal. Studies in Public Communication 2: 1-6.

29. Y Lee, Chan H, Jingjing W, Yi H (2008) The impacts of relational capital on self-disclosure in virtual communities, Information Technology \& People, ahead-of-print.

30. Dholakia R (2004) Gender and IT in the Household: Evolving Patterns of Internet Use in the United States. Journal The Information Society An International Journal 22(4): 231-240.

31. Erin E Hollenbaugh, Amber L Ferris (2014) Facebook self-disclosure: Examining the role of traits, social cohesion, and motives. Computers in Human Behavior 30: 50-58.

32. Tiffany A Pempek, Yevdokiya A Yermolayeva, Sandra L Calvert (2009) College students' social networking experiences on Facebook. Journal of Applied Developmental Psychology 30(3): 227-238. 
33. Pattim Valkenburg, Alexander P Schouten, 2006 M Upreti, V Kumar (2017) Learning the student's sufferings using Social Networks, Internationa Conference on Computing, Communication and Automation (ICCCA), Greater Noida pp. 319-322.

34. Joseph B Waltherl, Brandon Van Der Heide, Sang-Yeon Kim, David Westerman, Stephanie Tom Tong (2008) The Role of Friends' Appearance and Behavior on Evaluations of Individuals on Facebook: Are We Known by the Company We Keep? Human Communication Research 38(1): 2849.

35. Justice, K Schenk (Eds.), Encyclopedia of distance and online learning 2nd (Edn). Information Science Reference.

ISSN: $2574-1241$

DOI: $10.26717 /$ BJSTR.2020.28.004592

Chanyanan Somthawin pongsai. Biomed J Sci \& Tech Res

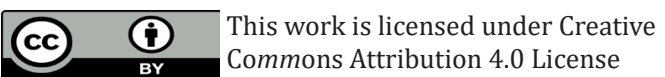

Submission Link: https://biomedres.us/submit-manuscript.php
36. Natalya N Bazarova, Yoon Hyung Choi (2014) Self-Disclosure in Social Media: Extending the Functional Approach to Disclosure Motivations and Characteristics on Social Network Sites. Journal of Communication 64(4): 635-657

37. Sheldon P (2009) I'll poke you. You'll poke me! Self-disclosure, social attraction, predictability and trust as important predictors of Facebook relationships. Cyberpsychology: Journal of Psychosocial Research on Cyberspace 3(2).

38. Shih YW, Meng H, De CL (2014) Self-disclosure interpersonal relationships and stickiness of online communities. Psychology and Behavioral Sciences 4(2): 71-78.

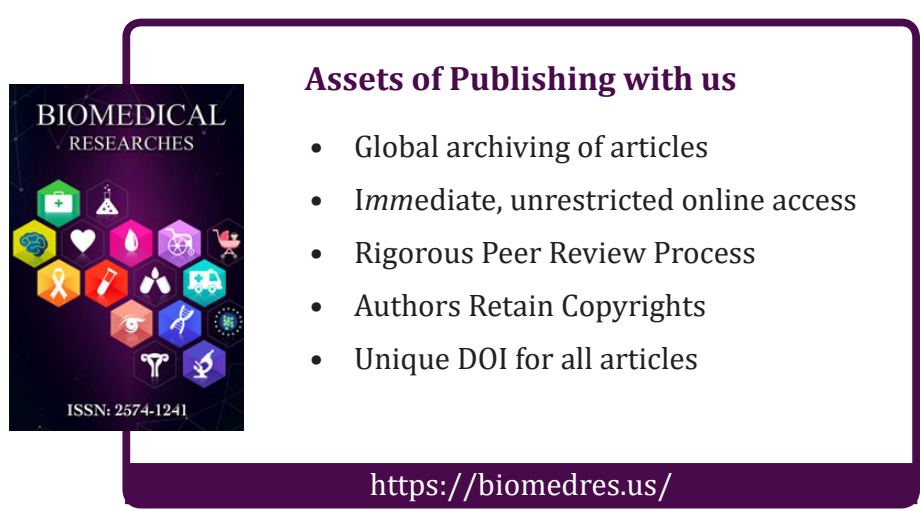

